\title{
Response to the gonadotropin releasing hormone agonist leuprolide in immature female sheep androgenized in utero
}

\author{
SERGIO E. RECABARREN ${ }^{1}$, TERESA SIR-PETERMANN ${ }^{2}$, ALEJANDRO LOBOS $^{1}$, \\ ETHEL CODNER ${ }^{3}$, PEDRO P. ROJAS-GARCÍA ${ }^{1}$ and VÍCTOR REYES ${ }^{1}$
}

\author{
${ }^{1}$ Laboratory of Animal Physiology and Endocrinology, Faculty of Veterinary Medicine, University of \\ Concepción, Chillán, Chile. \\ ${ }^{2}$ Laboratory of Endocrinology and Metabolism, Department of Internal Medicine, Faculty of Medicine, \\ University of Chile, Santiago, Chile. \\ ${ }^{3}$ Institute of Maternal and Child Research (IDIMI), Faculty of Medicine, University of Chile, Santiago, Chile.
}

\begin{abstract}
Similar to women with Polycystic Ovary Syndrome (PCOS), female sheep treated prenatally with testosterone (T-females) are hypergonadotropic, exhibit neuroendocrine defects, multifollicular ovarian morphology, hyperinsulinemia and cycle defects. Hypergonadotropism and multifollicular morphology may in part be due to developmentally regulated increase in pituitary responsiveness to $\mathrm{GnRH}$ and may culminate in increased ovarian estradiol production. In this study, we utilized a GnRH agonist, leuprolide, to determine the developmental impact of prenatal testosterone exposure on pituitary-gonadal function and to establish if prenatal exposure produces changes in the reproductive axis similar to those described for women with PCOS. Eight control and eight T-females were injected intravenously with $0.1 \mu \mathrm{g}$ of leuprolide acetate per kilogram of body weight at 5,10 and 20 weeks of age. Blood samples were collected by means of an indwelling jugular vein catheter at $0,3,6,9,12,18,24,30,36,42$ and 48 hours after leuprolide. Area under the curve (AUC) of $\mathrm{LH}$ response to leuprolide increased progressively between the three ages studied $(\mathrm{P}<0.05)$. AUC of LH in Tfemales was higher than in control females of the same age at 5 and 10 weeks of age $(\mathrm{P}<0.05)$, but similar at 20 weeks of age. AUC of estradiol response was lower at 10 but higher at 20 weeks of age in T-females compared to controls of the same age $(\mathrm{P}<0.05)$. Our findings suggest that prenatal $\mathrm{T}$ treatment alters the pituitary and ovarian responsiveness in a manner comparable to that observed in women with PCOS.
\end{abstract}

Key terms: androgenized females, fetal programming, PCOS, leuprolide, female sheep

\section{INTRODUCTION}

Experimental exposure to testosterone during fetal life in mammals, such as sheep and monkeys, or pathological exposure to high levels of androgens in humans produces a series of changes in the reproductive axis that become evident in their post-natal life (Abbot et al., 1998; Birch et al., 2003; West et al., 2001; New, 2003). Recently, it has been established that the prenatal androgen exposure (PAE) in females born to testosterone (T)-treated sheep or monkey mothers is associated with growth retardation, infertility, obesity and insulin resistance during adulthood, although some of these characteristics could be expressed early in the extra-uterine life (Eisner et al., 2000; Recabarren et al., 2003; 2005; Birch et al., 2003). Ovarian acyclicity, ovarian follicular disruption in prenatally $\mathrm{T}$-treated sheep manifested as a reduction in number of $2-\mathrm{mm}$ follicles, an increase in the size of large follicles and prolonged persistence, associated with hypergonadotropism comparable to those seen in PCOS, have been observed as well, all of which may be initiated early during post-natal life or during fetal development (Sharma et al., 2002; Birch et al., 2003; 
West et al., 2001; Padmanabhan et al., 1998).

The GnRH agonist test has been used in human clinical studies to define hypogonadotropic hypogonadism of the constitutional delay of puberty (Street et al., 2002; Lanes et al., 1997) and in humans and animals to evaluate the gonadal axis prior to puberty (Elsholz et al., 2004; Aravindakshan et al., 2000) and after puberty (Ghizzoni et al., 1996). The GnRH agonist produces a transitory hyperstimulation of the gonadotrope, which simultaneously allows the stimulation of the gonad by the endogenous gonadotropins (Bo-Abbas et al., 2001; Rosenfield et al., 1996.) The objective of the present study was to evaluate and compare the pituitary and ovary response to the $\mathrm{GnRH}$ agonist leuprolide in immature female sheep, comparing control sheep with prenatally testosterone-treated female sheep of 5, 10 and 20 weeks of age, thus including the late postnatal and early prepubertal period in order to determine the developmental impact of prenatal testosterone exposure on pituitary-gonadal function and to establish if prenatal androgen exposure produces changes in the reproductive axis similar to those described for the Polycystic Ovary Syndrome (PCOS) in humans.

\section{MATERIALS AND METHODS}

\section{General management of mothers and lambs}

Forty adult female Suffolk sheep were mated after a synchronized estrus following treatment with intravaginal progestagen pessaries (Eazy Breed) and prostaglandin (Genestren, Drug Pharma, Chile), in early March, during the natural breeding season. Females were randomly assigned to one of the two treatments. One group of 20 pregnant sheep received biweekly intramuscular injections of $60 \mathrm{mg}$ of testosterone propionate (Sigma, USA) dissolved in cottonseed oil (Kosut el al., 1997), beginning at 30 days of pregnancy until day 90. The remaining 20 pregnant sheep received the vehicle. Pregnant sheep were maintained under regular husbandry protocols supervised by the veterinary staff at the sheep facility of the Faculty of Veterinary Medicine, University of Concepción, Chillán, Chile. At birth, lambs were left undisturbed with their mothers for 4 hours to permit mother and newborn bonding, then the umbilicus was cleaned and disinfected, and the newborn lambs were weighed. The characteristics of the external genitalia were observed and the ano-genital distance recorded. Biometric data are given in table 1. Mothers and newborns were kept in a closed barn for the first five days after delivery in stalls housing 3 to 4 mothers each. Mothers were allowed to grass and were also supplemented twice a day with food pellets for lactating sheep. Newborns remained with their mothers until 10 weeks of age, when they were weaned. After weaning, lambs were given free access to water, pasture and supplemented twice a day with hay and commercial pellet food. Food pellets based on dry matter (made of oat, corn, wheat, gluten feed, gluten meal, soybean meal, fish meal, sunflower meal and mineral salts) contained $18 \%$ protein, $11 \%$ crude fiber, $2 \%$ fat and $2450 \mathrm{Kcal} / \mathrm{kg}$ (Glovigor, Compañía Molinera El Globo, Chile). Beginning at 17 weeks of age, a blood sample was collected by venipuncture once a week and from 20 weeks of age twice weekly to determine progesterone concentrations and to define onset of puberty. Plasma progesterone concentrations higher than $1 \mathrm{ng} / \mathrm{mL}$ in one single or in two consecutive samples were considered to represent a previous ovulation and. therefore, onset of puberty (Recabarren et al., 2004).

All procedures were revised and approved by the local ethical committee on animal research.

\section{GnRH agonist test}

Eight control and eight T-females, all of single birth, were selected for this study. The GnRH agonist test was conducted in all females at 5, 10 and 20 weeks of age. All procedures began at 14: $00 \mathrm{hrs}$. The GnRH agonist test consisted of the intravenous administration of $10 \mu \mathrm{g} / \mathrm{kg}$ body weight of 
leuprolide acetate (Lupron, Abbott Laboratory, Chile), through an previously inserted indwelling jugular vein catheter as described elsewhere (Recabarren et al., 1995). Blood samples were taken at $0,3,6$, $9,12,18,24,30,36,42$ and 48 hours after the leuprolide administration. Blood samples were received in heparinized tubes kept on ice and later spun at $1000 \mathrm{x}$ g for 15 min at $4^{\circ} \mathrm{C}$. Plasma was harvested and kept frozen at $-20^{\circ} \mathrm{C}$ until later measurements of LH and estradiol by RIA.

\section{Hormone measurements}

Plasma LH concentrations were determined by RIA using ovine radio-iodinated $\mathrm{LH}$ (LER 1374-A), ovine antiserum CSU-204 and ovine LH standard oLH-S25 (provided by NIADDK, USA), in $200 \mathrm{uL}$ duplicates, following procedures described elsewhere (Recabarren et al., 1996). The intra- and interassay coefficients of variation were 5 and $12 \%$, respectively. The minimal detectable $\mathrm{LH}$ dose, defined as $90 \%$ of buffer control, was $0.1 \mathrm{ng} / \mathrm{mL}$.

Plasma progesterone concentrations were measured by RIA, using commercial kits (DPC, USA). DPC kits are routinely used to measure plasma progesterone in animals and have been validated for sheep plasma. The intra- and interassay coefficients of variation were 2 and $5 \%$, respectively. The minimal detectable dose of progesterone, defined as $90 \%$ of control, was $0.1 \mathrm{ng} / \mathrm{mL}$.

Plasma estradiol concentrations were measured using commercial kits (Estradiol ultrasensitive-DSL, Webster, TX, USA) validated for sheep. The intra- and interassay coefficients of variation were 3 and $7 \%$, respectively. The minimal detectable dose of estradiol, defined as $90 \%$ of control, was $5 \mathrm{pg} / \mathrm{mL}$.

\section{Statistical analysis}

Plasma LH and estradiol concentrations present during the GnRH agonist test in each age and treatment group were analyzed by analysis of variance for repeated measures and comparisons of the means with the Newman-Keuls' test using the GB Stat v.5 program. Plasma LH and estradiol concentrations were transformed into area under the curve of response as the area of a polygon by the trapezoidal formula using a computer program based in Excell spreadsheet. These data were analyzed by analysis of variance for repeated measures with age as the repeated factor and comparison of the means with the Newman-Keuls' test using the GB Stat v.5 program. For all test, a $\mathrm{P}<0.05$ was considered statistically significant. Data are given as mean \pm standard error of the mean.

\section{RESULTS}

In the control group, one of eight sheep presented their first progesterone increase above $1 \mathrm{ng} / \mathrm{mL}$ at 22 weeks of age, another one at 24 weeks, and the last one at 29 weeks of age. Among the T-females, one of the eight sheep had progesterone levels above $1 \mathrm{ng} / \mathrm{ml}$ at 17 weeks when progesterone sampling began. Two Tfemale presented progesterone increases at 20 weeks of age, two at 27 weeks, one at 28 weeks, and another at 29 weeks. One Tfemale did not present progesterone increases until 30 weeks of age when progesterone sampling ended (Figure 1).

TABLE I

Biometric parameters in control and in androgenized pregnant female sheep at birth

\begin{tabular}{lccccc}
\hline & Pregancy (days) & $\begin{array}{c}\mathrm{N}^{\circ} \text { newborn/ } \\
\text { mother }\end{array}$ & $\begin{array}{c}\text { Number of mother } \\
\text { with twins }\end{array}$ & $\begin{array}{c}\text { Placenta } \\
\text { weight }(\mathrm{kg})\end{array}$ & $\begin{array}{c}\text { Ano-genital } \\
\text { distance }(\mathrm{cm})\end{array}$ \\
\hline Control & $147 \pm 1.8$ & 1.5 & $9.0 / 20.0$ & $0.44 \pm 0.03$ & 1.5 \\
Androgenized & $147 \pm 1.5$ & 1.6 & $11 / 20.0$ & $0.57 \pm 0.05$ & 15 \\
\hline
\end{tabular}




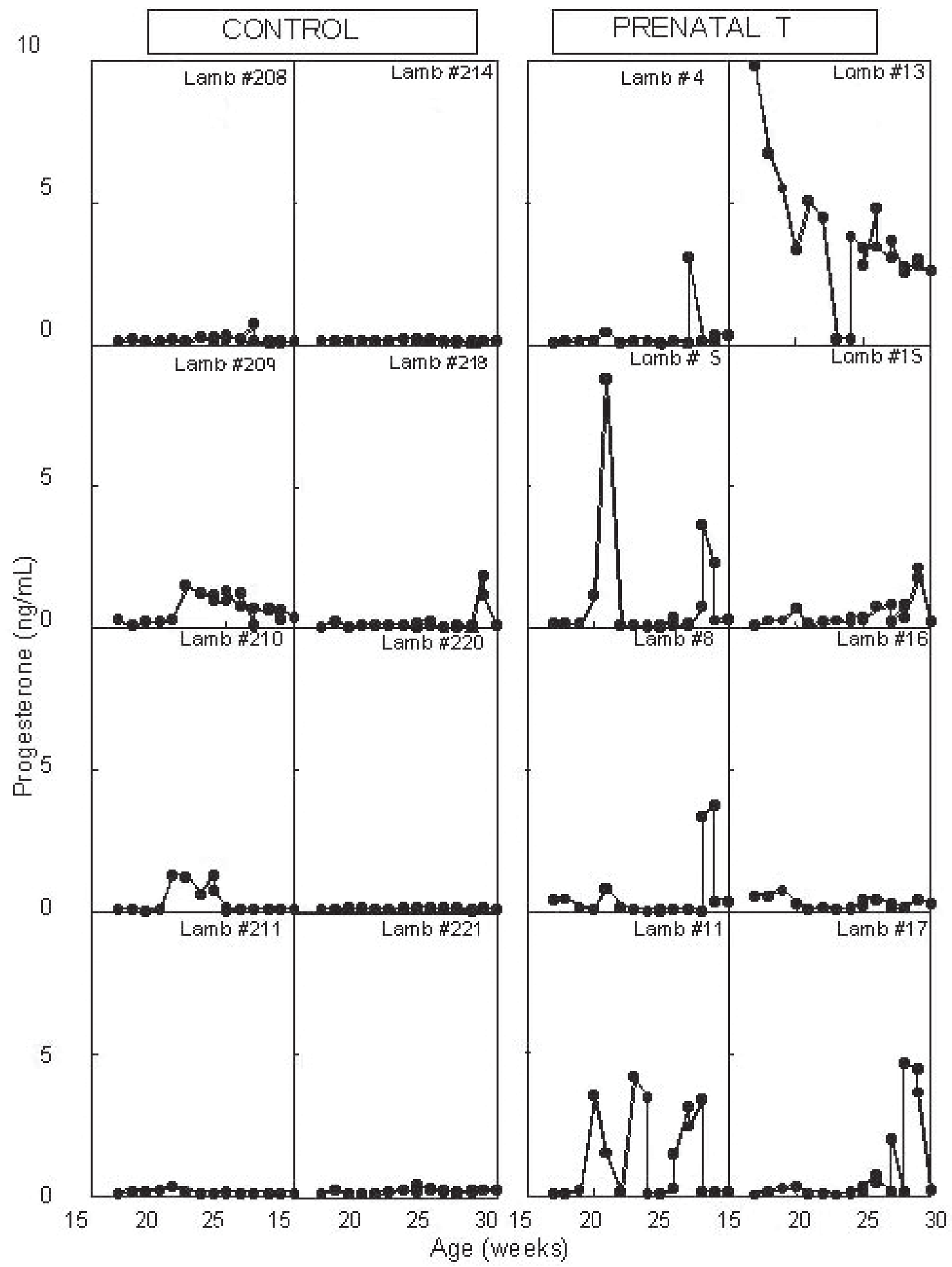

Figure 1. Plasma concentrations of progesterone in control (left panel) and in androgenized female sheep (right panel). Blood samples were drawn from 17 weeks of age until 30 weeks of age. Three control females had increases in progesterone over $1 \mathrm{ng} / \mathrm{ml}$ before 30 weeks of age. Seven Tfemales had progesterone increases over $1 \mathrm{ng} / \mathrm{ml}$ before 30 weeks of age. One did not exhibit any increase in progesterone. 
Figure 2 present the LH secretion profile in the control and T-females. The maximum LH level was observed at 3 hours postanalogue in both groups. Subsequently, plasma LH levels dropped until reaching basal levels 18 hours after leuprolide administration. In control sheep, the peak LH secretion in response to leuprolide increased significantly between 5, 10 and 20 weeks of age, while in the T-females, the maximum LH concentrations did not differ statistically between the three ages. However, T-females of 5 and 10 weeks of age had peak LH concentrations in response to leuprolide greater than in the control group $(\mathrm{P}<0.05)$.For 30 -week-old female sheep, the response to leuprolide is greater for the control group than for the $\mathrm{T}$-females $(\mathrm{P}<0.01)$ (Table 2$)$.

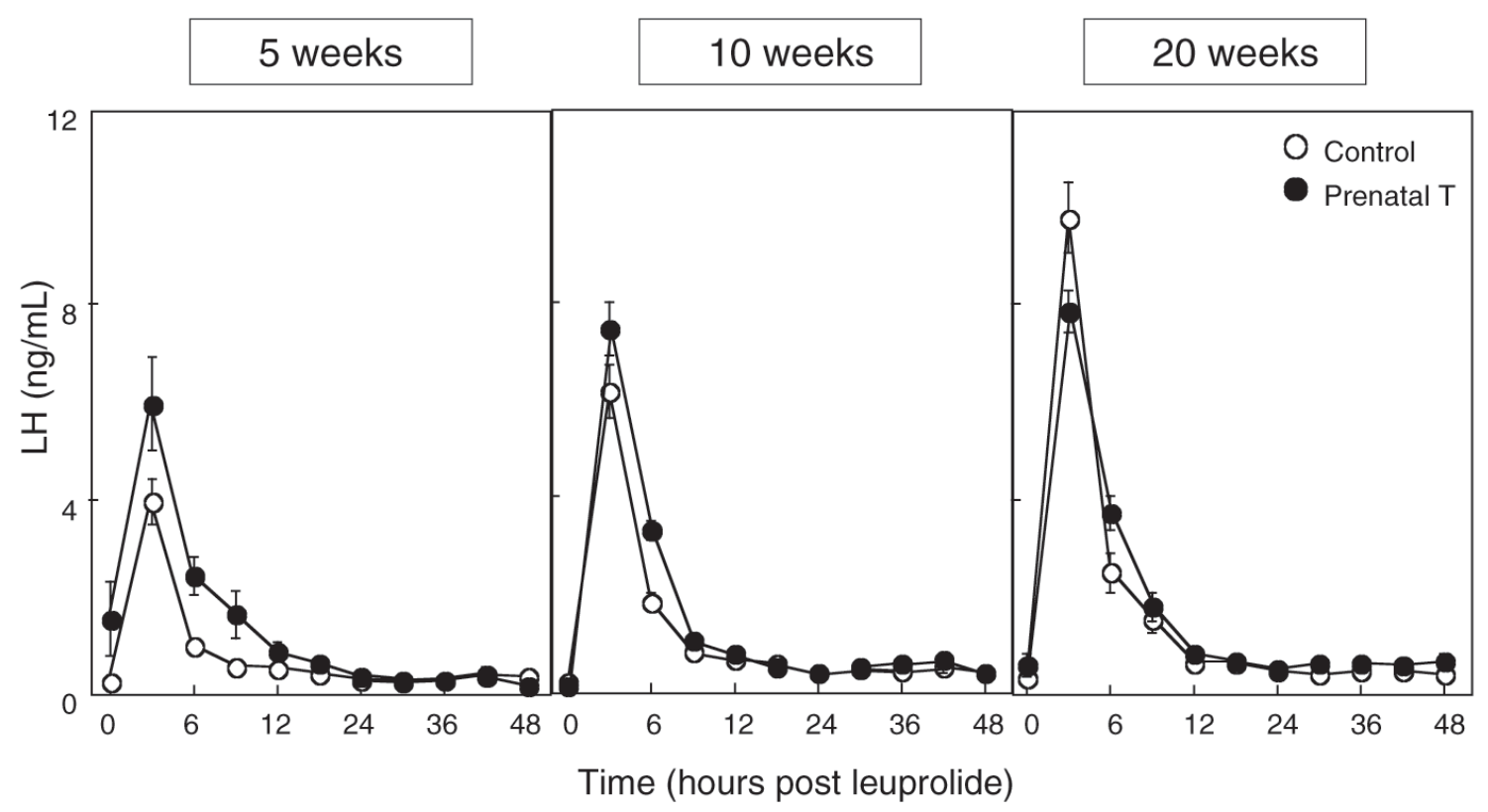

Figure 2. Mean $( \pm \mathrm{sem})$ plasma LH concentrations $(\mathrm{ng} / \mathrm{ml})$ in response to leuprolide at 5,10 and 20 weeks of age control (O-O) and T-females (-) T-females were born to mothers exposed to testosterone from day 30-90 of pregnancy.

TABLE II

Peak LH secretion after GnRH agonist leuprolide in control and in T-females. CONTROL FEMALES

\begin{tabular}{lcc}
\hline 5 WEEKS & 10 WEEKS & 20 WEEKS \\
\hline $3.94 \pm 0.48 \mathrm{a}$ & $6.18 \pm 0.55 \mathrm{~b}$ & $9.78 \pm 0.73 \mathrm{c}$ \\
\hline T- FEMALES & & \\
\hline 5 WEEKS & 10 WEEKS & 20 WEEKS \\
\hline $5.95 \pm 0.96 \mathrm{x}$ & $7.46 \pm 0.52 \mathrm{x}$ & $7.85 \pm 0.44 \mathrm{x}$ \\
\hline
\end{tabular}


The areas under curve of LH secretion in the control and androgenized females are presented in Figure 3.The area under the LH curve increased significantly in the control group from $29.54 \pm 3$ at 5 weeks to $60.3 \pm 3.1 \mathrm{ng} / \mathrm{ml} / 48 \mathrm{hr}$ at 20 weeks of age $(\mathrm{P}<0.01)$. In the $\mathrm{T}$-females, the areas under the curve of 5-week-old and 10-week-old sheep were not different $(47.9 \pm 7$ vs. 56.3 $\pm 5.7 \mathrm{ng} / \mathrm{ml} / 48 \mathrm{~h}$ ). The area under the $\mathrm{LH}$ curve in the 20-week-old T-female is greater than the area presented by the 5week-old T-females (64.54 \pm 0.9 vs. $47.9 \pm 7$, $\mathrm{P}<0.05)$. When both groups are compared by ages, the area under the curve is greater in the 5-week-old and 10-week-old T-females compared with the control group of the same age $(\mathrm{P}<0.01$ and $\mathrm{P}<0.05$ respectively).

The estradiol secretion profiles in 10 week-old and 20-week-old sheep from both groups are presented in Figure 4.The secretion profiles for 5-week-old females are not presented, since measured levels were below the RIA sensitivity level $(5 \mathrm{pg} /$ $\mathrm{mL}$ ). In 10-week-old and 20 week-old females, the secretion pattern differed between the control and T-females. In the control group, estradiol secretion was lower at 20 weeks of age than at 10 weeks of age, the first significant increase above the basal concentrations being observed at 24 hours post-leuprolide. In contrast, in the T-females, the response increased between 10 and 20 weeks of age. In 20-week-old T-females, the response was faster and greater than the response presented by 10 -week-old $\mathrm{T}$ females. The first significant increase of estradiol appeared at 24 hours in the 20-weekold T-females and at 30 hours for 10-weekold T-females. Additionally, estradiol secretion is significantly greater in the 20week-old T-females than in the control group of the same age. This difference is observed in the area under the curve of estradiol secretion that is presented in Figure 3.

\section{DISCUSSION}

Results from the present study show that prenatal exposure to androgens during a limited time span of sheep pregnancy is associated in the offspring with a masculinization of the genitalia, a tendency to an early onset of puberty, greater pituitary gland sensitivity to leuprolide and high ovary sensitivity to endogenous LH stimulation in comparison with control
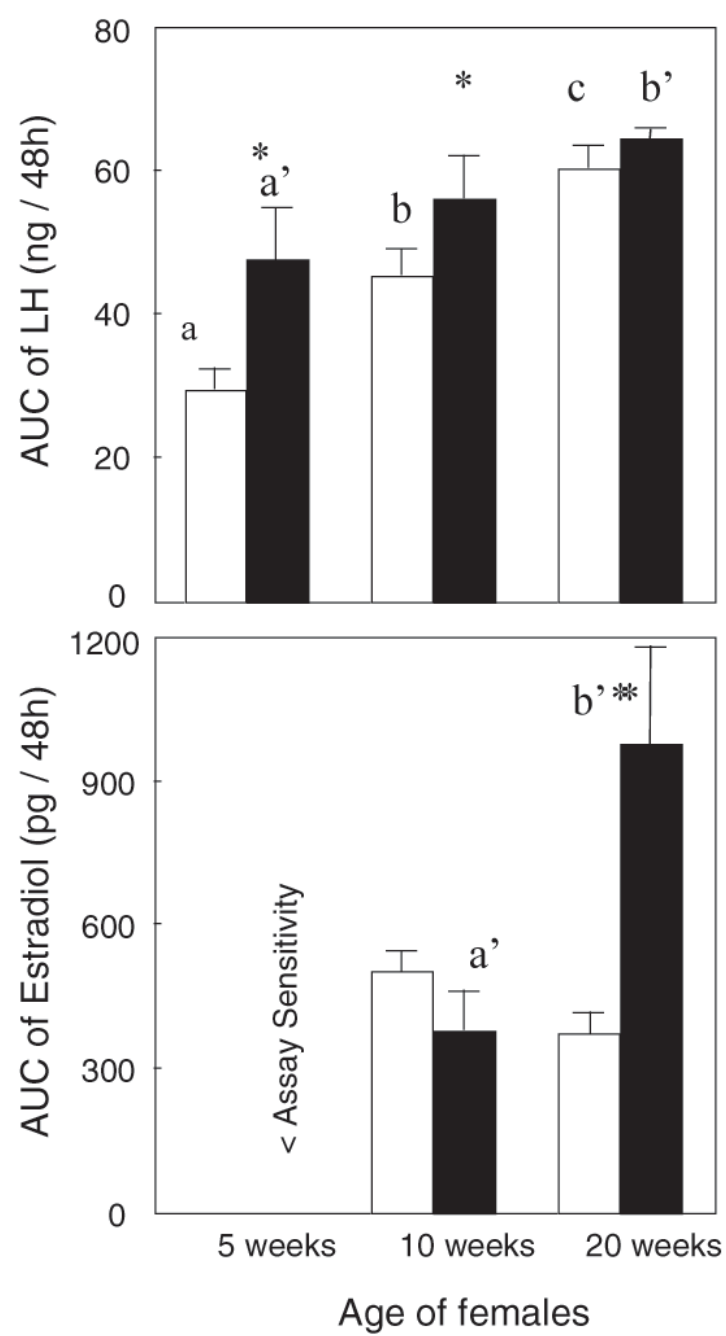

Figure 3. Mean $( \pm$ sem $)$ area under the curve (AUC) of LH response (upper panel) and estradiol response (lower panel) to leuprolide in control (open columns) and in T-females. AUC of LH increased significantly in control females ( $a, b, c$ P $<0.05)$ while in androgenized females area was higher in females of 20 (a', b') weeks compared to 5 weeks of age. AUC of LH in androgenized females of 5 and 10 weeks was higher than in control females of the same age $(* \mathrm{P}<0.05)$. AUC of estradiol was higher in $\mathrm{T}$ females of 20 weeks than in T-females of 10 weeks of age or in control females of the same age $(* \mathrm{P}<0.05)$. 


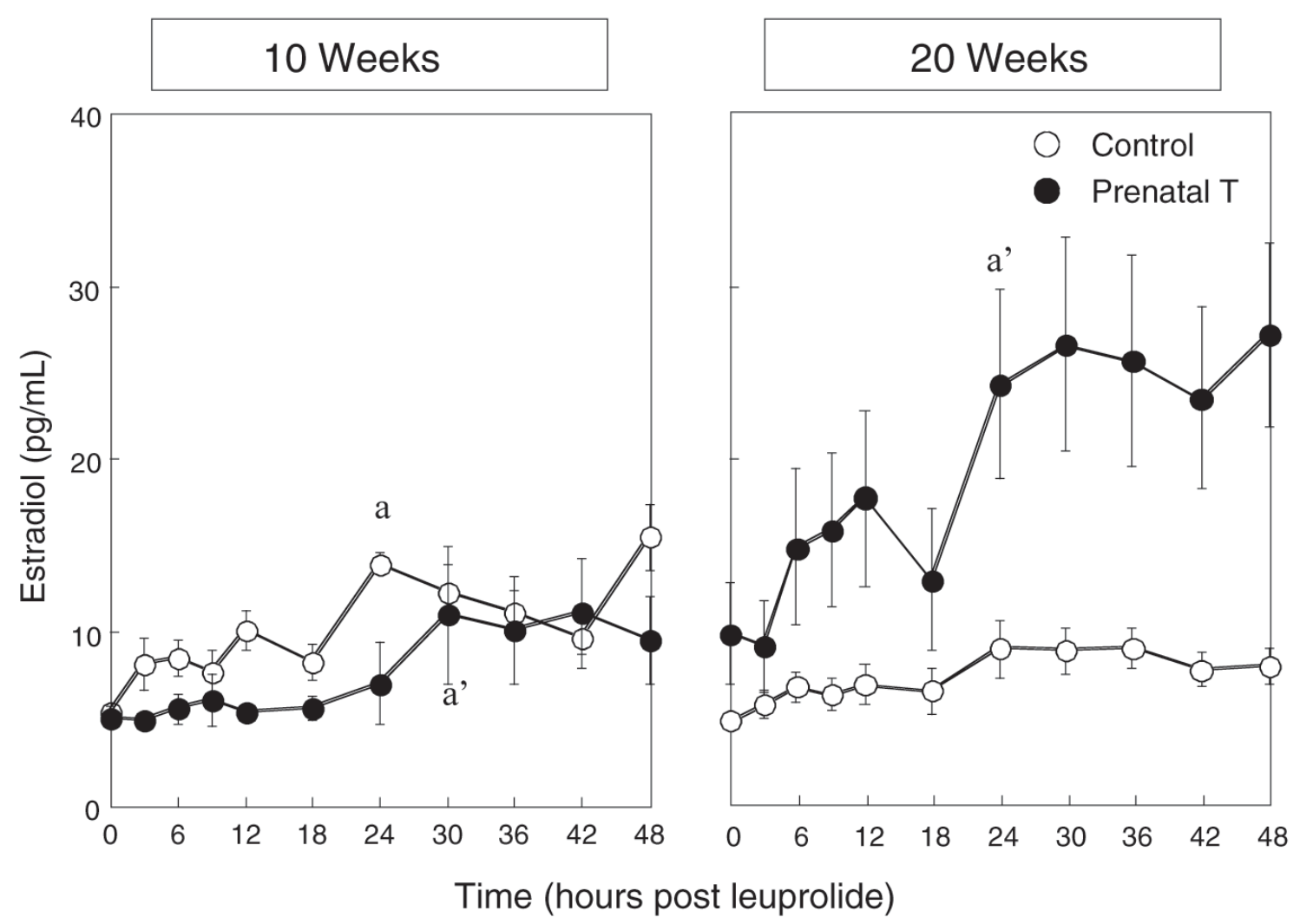

Figure 4. Mean ( \pm sem) plasma estradiol concentrations $(\mathrm{pg} / \mathrm{ml})$ in response to leuprolidein control (O-O) and in T-females (-) of 5, 10 and 20 weeks of age.

females. Studies in female sheep exposed to testosterone in uterus with a scheme of treatment similar to the present study but with a higher dose (100 mg testosterone propionate biweekly), showed that the preovulatory-like surge of $\mathrm{LH}$ was not present in either gonadectomized males or females when stimulated with a preovulatory dosis of estradiol. On the other hand, females exposed to testosterone in uterus displayed an increase in tonic LH secretion at an age similar to that of males (Kosut et al., 1997). This early increase in tonic LH secretion is defined as a neuroendocrine puberty, since ovaries are absent. These phenomena are attributed to the masculinization of the hypothalamic GnRH pulse generator (Wood et al., 1991; Wood et al., 1995; Herbosa et al., 1996). In normal control females, the tonic increase in $\mathrm{LH}$ secretion begins at 30 weeks of age in contrast to the earlier initiation of tonic $\mathrm{LH}$ secretion, which is usually displayed at 10 weeks of age in T-females (Wood et al., 1991; Wood et al., 1995). However, in other studies of prenatally androgenized females with intact ovaries, females unexpectedly did not show the early increase in tonic LH secretion leading to puberty but rather puberty was achieved at the same time as controls (Sharma et al., 2002; Birch et al., 2003). Our results provide additional support to the findings of Sharma and colleagues (2002), since we observed that the onset of puberty in two androgenized females was almost coincident with two control females. However, the total number of females showing progestogenic cycles was greater in androgenized than in control females. Additionally, in the study of Sharma and colleagues (2002) the duration of the breeding season and the number of cycles that occurred during the first breeding season were similar between control and prenatally androgenized sheep. In contrast, prenatal exposure to androgens 
compromised the positive feedback effects of estradiol. This does not seem to be our case because the estradiol positive feedback should have provoked progestogenic cycles. It is therefore possible that the lower dose of testosterone used in our study did not completely compromise the estradiol positive feedback and ovulation did occur in these sheep.

Leuprolide has been used in human and animal studies. In boys and girls, leuprolide acetate stimulates gonadotropin and gonadal steroid secretion during puberty in both sexes (Potau et al, 1999).The results from the present study indicate that the GnRH agonist stimulated both the pituitary gland and the ovary in both groups. The sensitivity of the pituitary gland to the leuprolide challenge (measured as AUC of LH) differed between the control and T-females. In control females, the sensitivity is low at 5 weeks of age and increased as the female matured. This change in sensitivity may represent a combination of factors including decrease in negative estrogen feedback on the pituitary gland and an increase in the number of $\mathrm{GnRH}$ receptors as a consequence of tonic GnRH release. (Viscarra et al., 1997; Turzillo et al., 1998). On the other hand, the $\mathrm{LH}$ release in response to leuprolide in androgenized females did not change between females of five and ten weeks of age. However, at both ages, the LH release was higher than in control females. Female sheep exposed prenatally to testosterone (Kosut et al., 1997) or DHT (Masek et al., 1999) initiate their increase in tonic LH secretion between seven and ten weeks of age due to a decrease in negative estradiol feedback. The reduction in negative feedback may have increased GnRH tonic secretion, and this increase in GnRH secretion in turn should have primed the pituitary gland to the GnRH agonist stimulation. This may explain the difference between both groups. The pituitary gland of Tfemales may be secreting large amounts of $\mathrm{LH}$, since its secretion does not increase further between 5 and 20 weeks of age as it does in control females. In keeping with this, the AUC of LH secretion is similar between 5-week-old T-females when compared to 10 -week-old and 20-week-old control females, suggesting that pituitary secretion in T-females matures earlier and became stabilized at 20 weeks of age.
Estradiol secretion was observed in both groups of female at 10 and 20 weeks of age after leuprolide, however it was not possible to determine estradiol secretion in 5-week-old females. The exaggerated $\mathrm{LH}$ response in $\mathrm{T}$ females of 5 weeks of age did not correspond with estradiol secretion, suggesting that the ovary was not fully competent to respond to the endogenous LH stimulation or the bioactivity of LH was not comparable with the immunoactivity measured by RIA at that early age. However, at 20 weeks of age, a high response was observed in T-females. In androgenized adult female monkeys, a high response to recombinant HCG in testosterone and 17alfa hydroxyprogesterone was also observed after 24 hours of stimulation. The exaggerated thecal cell steroid response to recombinant $\mathrm{hCG}$ in the prenatally androgenized female monkeys was attributed to a heightened 17 a-hydroxylase activity of cytochrome P450c17a, a key enzyme in ovarian thecal cell steroid production (Eisner et al., 2002). Recent evidence has also shown that in addition to 17 a-hydroxylase, increased $\mathrm{T}$ production in PCOS theca cells does not result from deregulation of "androgenic" 17 aHSD activity or altered expression of AKRs that may express 17 aHSD activity but rather the increased synthesis of $\mathrm{T}$ precursors is the primary factor driving enhanced $\mathrm{T}$ secretion in PCOS (Nelson et al., 2001). In PCO women, during the early follicular phase the administration of leuprolide led to an increased androgen secretion and 17-OHP compared to normal women. There was also a high response in normal women with ovaries classified by ultrasound as polycystic but not corresponding to women with PCO, because other endocrinological and metabolic features were absent (Chang et al., 2000). Authors attributed this high ovarian steroid secretion as an abnormality in the 17-hydroxylase and $\mathrm{C}-17,20$ lyase in the ovarian delta 4 pathway, comparable to that observed in PCO. It is then possible to speculate that the ovary of $\mathrm{T}$ females in our study also present such abnormalities with an overproduction of androstenodione and testosterone, which is later converted to estradiol. On the other hand, the exaggerated ovarian response could be a consequence of alterations in the ovarian development and folliculogenesis in 
androgenized lambs. Such alterations may include an inhibition in apoptosis of granulose cells similar to what has been proposed to occur in fetuses from ewes nutritionally restricted during pregnancy (Borwick et al., 1997). These fetus showed $50 \%$ more oocytes than fetus from adequately fed mothers, a finding that was interpreted as a delay in the normal process of oogonial degradation by phagocytosis of oocytes (Borwick et al., 1997). Further work is needed to clarify the underlying disturbances leading to an exaggerated response in the ovary of androgenized female sheep.

In summary, the present study shows that the pituitary gland and the ovary of androgenized female sheep are altered from an early age in prepubertal development. The exaggerated estradiol secretion at 20 weeks of age suggest that abnormalities in the secretary pathway are already established and may contribute to subsequent infertility problems in the mature stage, as suggested in adolescents with PCOS.

\section{ACKNOWLEDGEMENTS}

Authors express their appreciation to Dr. Gordon D. Niswender, Dr. Leo E. Reichert Jr. and to the NIADDK for providing reagents for the ovine LH radioimmunoassay. To Prof. José Parilo, for providing female sheep for breeding and feeding advise. To Dr. Fernando Saravia, Dr. Marianela Caballero and Dr. José Cox, from the Laboratory of Reproductive Biotechnology, for estrous synchronization and programmed breeding of sheep. To Dr. Vasantha Padmanabhan, University of Michigan for her assistance with figures and scientific input. To Ms. Jeanne Simon for her help with the English edition. This work was supported by Fondecyt Research grant 1020232.

\section{REFERENCES}

ABBOTT DA, DUMESIC DA, EISNER JR, GOY RW (1998) Insights into the development of PCOS from studies of prenatally androgenized female rhesus monkeys. Trends Endocrinol Metab 9: 62-67

ARAVINDAKSHAN JP, HONARAMOOZ A, BARTLEWSKI PM, BEARD AP, PIERSON RA,
RAWLINGS NC (2000) Pattern of gonadotropin secretion and ultrasonographic evaluation of developmental changes in the testis of early and late maturing bull calves. Theriogenology 54: 339-354

BIRCH RA, PADMANABHAN V, FOSTER DL, UNSWORTH WP, ROBINSON JE (2003) Prenatal programming of reproductive neuroendocrine function: Fetal androgen exposure produces progressive disruption of reproductive cycles in sheep. Endocrinology 144: 1426-1434

BO-ABBAS YY, MARTIN KA, LIBERMAN RF, CRAMER DW, BARBIERI RL (2001) Serum and follicular fluid hormone levels during in vitro fertilization after short- or long-course treatment with a gonadotropin-releasing hormone agonist. Fertil Steril 75: 694-699

BORWICK SC, RHIND SM, MCMILLEN SR, RACEY PA (1997) Effect of undernutrition of ewes from the time of mating on fetal development in mid gestation. Reprod Fert Dev 9: 711-715

CHANG PL, LINDHEIM SR, LOWRE C, FERIN M, GONZÁLEZ F, BERGLUND L, CARMINA E, SAUER MV, LOBO RA (2000) Normal ovulatory women with polycystic ovaries have hyperandrogenic pituitary-ovarian responses to gonadotropin-releasing hormone-agonist testing. J Clin Endocrinol Metab 85: 995- 1000

GHIZZONI L, VIRDIS R, VOTTERO A, CAPPA M, STREET ME, ZAMPOLLI M, IBANEZ L, BERNASCONI S (1996) Pituitary-ovarian responses to leuprolide acetate testing in patients with congenital adrenal hyperplasia due to 21-hydroxylase deficiency. J Clin Endocrinol Metab 81: 601-606

EISNER JR, DUMESIC DA, KEMNITZ JW, ABBOTT DH (2000) Timing of prenatal androgen excess determines differential impairment in insulin secretion and action in adult female rhesus monkeys. J Clin Endocrinol Metab 85: 1206-1210

EISNER JR, BARNETT MA, DUMESIC DA, ABBOTT DH (2002) Ovarian hyperandrogenism in adult female rhesus monkeys exposed to prenatal androgen excess. Fert Steril 77: 167-172

ELSHOLZ DD, PADMANABHAN V, ROSENFIELD RL, OLTON PR, PHILLIPS DJ, FOSTER CM (2004) GnRH agonist stimulation of the pituitary-gonadal axis in children: Age and sex differences in circulating inhibin-B and activin-A. Hum Reprod 19: 2748-2758

HERBOSA CG, DAHL GE, EVANS NP, PELT J, WOOD RI, FOSTER DL (1996) Sexual differentiation of the surge mode of gonadotropin secretion: Prenatal androgens abolish the gonadotropin-releasing hormone surge in the sheep. J Neuroendocrinol 8: 627-633

KOSUT SS, WOOD RI, HERBOSA-ENCARNACION C, FOSTER DL (1997) Prenatal androgens time neuroendocrine puberty in the sheep: Effect of testosterone dose. Endocrinology 138: 1072-1077

LANES R, GUNCZLER P, OSUNA JA, PALACIOS A, CARRILLO E, RAMÍREZ X, GARCÍA C, PAOLI M, VILLAROEL O (1997) Effectiveness and limitations of the use of the gonadotropin-releasing hormone agonist leuprolide acetate in the diagnosis of delayed puberty in males. Horm Res 48: 1-4

MASEK KS, WOOD RI, FOSTER DL (1999) Prenatal dihydrotestosterone differentially masculinizes tonic and surge modes of luteinizing hormone secretion in sheep. Endocrinology 140: 3459-3466

NELSON VL, QIN KN KN, ROSENFIELD RL, WOOD JR, PENNING TM, LEGRO RS, STRAUSS JF 3rd, MCALLISTER JM (2001) The biochemical basis for increased testosterone production in theca cells 
propagated from patients with polycystic ovary syndrome. J Clin Endocrinol Metab 86: 5925-5933

NEW MI (2003) Inborn errors of adrenal steroidogenesis. Mol Cell Endocrinol 211: 75-83

PADMANABHAN V, EVANS N, TAYLOR JA, ROBINSON JE (1998) Prenatal exposure to androgens leads to the development of cystic ovaries in the sheep. Biol Reprod 56: (Suppl 1)194

POTAU N, IBÁNEZ L, SENTIS M, CARRASCOSA A (1999) Sexual dimorphism in the maturation of the pituitary-gonadal axis, assessed by GnRH agonist challenge. Eur J Endocrinol 141: 27-34

RECABARREN SE, URRUCELQUI A, ROBBIANO M, LOBOS A, ORELLANA P, PARILO J (1995) Effect of arginine and ornithine infusions on secretion of the growth hormone in prepubertal ewes. Arch Med Vet 27: 99-104

RECABARREN SE, ESCOBAR H, LOBOS A, RECABARREN MP, PARILO J (1996) Luteinizing hormone pulse frequency is increased by arginine infusions in prepubertal sheep. Exp Clin Endocrinol 104: $72-77$

RECABARREN SE, LOBOS A, CORNER E, PADMANABHAN V, FOSTER DL, SIRPETERMANN T (2003) Insulin sensitivity indices of male and female lambs differ during the early postnatal period in the absence of differences in detectable sex steroids. 85th Annual Meeting of the Endocrine Society, Philadelphia, PA, June 19-22, 2003. Abstract P2-256

RECABARREN SE, LOBOS A, TORRES V, OYARZO R, SIR-PETERMANN T (2004) Secretory patterns of leptin and luteinizing hormone in food-restricted young female sheep. Biol Res 37: 371-384

RECABARREN SE, PADMANABHAN V, CODNER E, LOBOS A, DURÁN C, VIDAL M, FOSTER DL, SIRPETERMANN T (2005) Postnatal developmental consequences of altered insulin sensitivity in female sheep treated prenatally with testosterone. Am J Physiol Endocrinol Metab accepted for publication.

ROSENFIELD RL, PEROVIC N, EHRMANN DA,
BARNES RB (1996) Acute hormonal responses to the gonadotropin releasing hormone agonist leuprolide: Dose-response studies and comparison to nafarelin - A clinical research center study. J Clin Endocrinol Metab 81: 3408-3411

SHARMA TP, HERKIMER C, WEST C, YE W, BIRCH R, ROBINSON JE, FOSTER DL, PADMANABHAN V (2002) Fetal programming: Prenatal androgen disrupts positive feedback actions of estradiol but does not affect timing of puberty in female sheep. Biol Reprod 66: 924-933

STREET ME, BANDELLO MA, TERZI C, IBÁNEZ L, GHIZZONI L, VOLTA C, TRIPODI C, VIRDIS R (2002) Leuteinizing hormone responses to leuprolide acetate discriminate between hypogonadotropic hypogonadism and constitutional delay of puberty. Fertil Steril 77: 555-560

VISCARRA JA, WETTEMANN RP, BRADEN DT, TURZILLO AM, NETT TM (1997) Effect of gonadotropin-releasing hormone $(\mathrm{GnRH})$ pulse frequency on serum and pituitary concentrations of luteinizing and follicle-stimulating hormone, GnRH receptors, and messenger ribonucleic acid for gonadotropin subunits in cows. Endocrinology 138: 594-601

TURZILLO AM, NOLAN TE, NETT TM (1998) Regulation of gonadotropin-releasing hormone (GnRH) receptor gene expression in sheep: Interaction of $\mathrm{GnRH}$ and estradiol. Endocrinology 139: 4890-4894

WEST C, FOSTER DL, EVANS NP, ROBINSON J, PADMANABHAN V (2001) Intra-follicular activin availability is altered in prenatally-androgenized lambs. Mol Cell Endocrinol 185: 51-59

WOOD RI, EBLING FJ, I'ANSON H, BUCHOLTZ DC, YELLON SM, FOSTER DL (1991) Prenatal androgens time neuroendocrine sexual maturation. Endocrinology 128: $2457-2468$

WOOD RI, MEHTA V, HERBOSA CG, FOSTER DL (1995) Prenatal testosterone differentially masculinizes tonic and surge modes of luteinizing hormone secretion in the developing sheep. Neuroendocrinology 62: 238-247 